\title{
Foreword III
}

\section{Scott Farrant}

Music copyright, or more accurately intellectual property (IP), are not typically terms that strike most music creators as sexy. They're not part of the creative process; they don't help with finding the right sound or a killer lick, nor do they allow a creator to connect to their audience or great co-writers.

Overall there's a very good chance that the majority of creators, especially those in the early part of their careers, will not want to pay any attention whatsoever to this subject; they'd rather be in the studio writing or recording, or out performing to their fans. But let's be honest here, put purely and simply: this is a big mistake.

Having worked in the music industry for more than 30 years, I have to say that 'IP-blindness' is one of the biggest avoidable causes of grief and trouble that a creator will experience as their career develops. IP is the bedrock of a creator's bread and butter: without IP creators would receive a mere fraction of what they do today. Imagine a world where Spotify, Apple Music, YouTube, Netflix, Network television companies, radio stations and many many more didn't have an obligation to pay royalties. It's IP that forces these entities to pay royalties and it is the contracts around IP that govern who gets paid what from this income. Importantly, IP is the framework under which publishing, recording and commissioning contracts are signed. A bad contract can be devastating to a creator's career through potential loss of ownership, loss of revenue, or loss of control over how they work, who they work with or even how they look and what they can and can't say or endorse. Think of it akin to going to work but never asking what your wages are, whether you get a lunch break, who you'll be working with and what you have to wear. 
But IP pops up in other ways, too - for example, in sampling or interpolating other creators' songs. You may be inspired by someone else's song but is the chord progression or riff you've used plagiarism, leaving you exposed to legal action? Typically, clearing samples or interpolations after the fact is far more costly than clearing them up front.

So, whether the issue is not paying sufficient attention to a publishing or recording contract, or failing to clear a sample, or not being aware of what obligations you might have to a fellow band member, IP is and should be treated as a central tenant of a creator's working life.

This book sets out to simplify and demystify copyright in all its guises, using many real-life examples that help explain often complex situations. This book should appeal to both those who already understand some of the elements of copyright and want to delve deeper and, importantly, to everyone who hasn't ever had exposure to the ideas and principles of copyright. Drawing on real-life examples of how copyright is used and keeping the language at a comprehensible level allows both the substance and the deeply interesting nature of the subject matter to be brought across. This book is an engaging, interesting and well-paced read and Hayleigh even allows some of her good humour to shine through. Hayleigh keeps the language clear and understandable and thankfully avoids that persistent habit lawyers have of dressing things up in Latin.

Scott Farrant Head of Global Publishing Operations, Kobalt 